\title{
Stochastic analysis of inter- and intra-laminar damage in notched PEEK laminates
}

\author{
M. Naderi, M. M. Khonsari* \\ Department of Mechanical Engineering, Louisiana State University, LA 70803 Baton Rouge, USA
}

Received 21 October 2012; accepted in revised form 13 January 2013

\begin{abstract}
This paper presents a finite element model to predict the progressive damage mechanisms in open-hole PEEK (Poly-Ether-Ether-Ketone) laminates. The stochastic laminate's properties with non-uniform stress distribution are considered from element to element using the Gaussian distribution function. The failure modes considered are: fiber tension/ compression, matrix tension/compression, fiber/matrix shear, and delamination damage. The onset of damage initiation and propagation are predicted and compared with three different failure criteria: strain-based damage criterion, Hashin-based degradation approach and stress-based damage criterion which is proposed by the authors of the present work. The interlaminar damage modes associated with fiber/matrix shearing and delamination are modeled using the cohesive elements technique in ABAQUS ${ }^{\mathrm{TM}}$ with fracture energy evolution law. Mesh sensitivity and the effect of various viscous regularization factors are investigated. Damage propagation and failure path are examined by re-running the program for several times.
\end{abstract}

Keywords: polymer composites, modeling and simulation, damage mechanism, cohesive element, stochastic material properties

\section{Introduction}

Fiber reinforced thermoplastic composite laminates are in high demand in advanced aerospace structures owing to their light weight, high stiffness, high strength, good toughness, long durability, superior impact resistance and favorable damagetolerance properties. Yet, despite many advantages compared to their metal counterparts, these laminates are not exempt from deterioration and damage, especially in the presence of a stress concentration. Of particular interest here is to study a common type of thermoplastic composite known as AS4/PEEK laminate composed of poly-ether-etherketone (PEEK) reinforced by AS4 carbon fiber. We seek to predict the strength of this type of laminate in the presence of stress concentration in the form of a hole or a notch in pinned- and bolt-joints. This information is useful at the design stage.
It is appropriate to begin with a brief survey of the open literature since numerous investigations dedicated to the prediction of progressive damage and strength of the laminates with stress concentrations already exist. For example, Chang et al. [1] studied the progressive damage for T300/976 graphite epoxy containing a hole under tensile loading using the modified Hashin [2] failure criteria. Their approach was to reduce the material properties to zero when failure criteria is satisfied by implementing the socalled 'sudden degradation rule'. Lessard and Shokrieh [3] modified Hashin failure criteria by taking into account the non-linear characteristic of material as well as implementing the sudden material degradation rule. Dano et al. [4] investigated the bearing strength of glass/epoxy pinned-joint laminates using the commercial software ABAQUS ${ }^{\text {TM }}$. Later, Icten and Karakuzu [5] investigated different

\footnotetext{
${ }^{*}$ Corresponding author, e-mail: khonsari@me.lsu.edu (C) BME-PT
} 
failure modes and bearing strength in woven carbon/epoxy laminates using the failure criteria proposed by Hoffman [6] and Hashin [2] both numerically and experimentally. Maa and Cheng [7] developed a failure model using the continuum damage mechanics (CDM)-based failure model using elastic-plastic constitutive equations implemented in ABAQUS. Also reported was their experimental data for AS4/PEEK laminates containing a circular hole. In a similar way, Ding et al. [8] carried out a three-dimensional finite element analysis of an open-hole thermoplastic AS4/PEEK laminate to interpret the results of their experimental observations.

To consider delamination and inter-laminar damage, Lapczyk and Hurtado [9] developed an anisotropic damage model for predicting failure and post-failure behavior in fiber reinforced materials based on the concept of fracture energy dissipation. They addressed the convergence of the numerical model in the softening regime by introducing a viscous regularization factor in the computations. Recently, Falzon and Apruzzese [10] carried out a threedimensional CDM-based model in ABAQUS/ Explicit to simulate the intra-laminar degradation of fiber-reinforced laminates based on ply failure mechanisms. Their focus was on the non-linear response of the shear failure mode and the interaction with other failure modes.

Recent literature in mechanic-based understanding and modeling of progressive damage analysis and prediction of strength of composite laminates specially notched laminates in composite research community contains many noteworthy studies such as the works reported by Camanho et al. [11], Abisset et al. [12], van der Meer et al. [13] and Fang et al. [14], Daghia and Ladeveze [15]. Among them, Camanho et al. [11] examined a continuum damage model to predict the strength and size effects of notched carbon-epoxy laminates. They experimentally and analytically studied the effects of size and the development of a fracture process zone before final failure. Abisset et al. [12] investigated progressive degradation in an open-hole IM7/8552 carbon/epoxy laminate using a damage mesomodel developed based on a micromechanical approach. They compared experimental and numerical results considering the ply's thickness and the in-plane scaling effect to capture the change in failure mode and the effect of the specimen's scale on tensile strength. Van der Meer et al. [13] simulated progressive failure, matrix cracking, interface elements for delamination, and a continuum damage model for fiber failure using phantom-node computational method. They validated their computational framework against experimental observations for openhole tests and compact tension tests. Fang et al. [14] presented a new augmented finite element method (A-FEM) which can account for arbitrary crack path, and different intra-element discontinuities. They showed that within their new formulation one is able to derive an explicit and fully condensed elemental equilibrium equations using augmented elements without additional external nodes or degree of freedom.

A survey of the published works clearly reveals that while substantial progress has been made especially in computational simulation of composites failure, predicting their progressive failure and arbitrary crack path considering randomness in material properties distribution remain a challenging task due to the complexity of the interactions among multiple damage processes. While some computational methods, i.e. phantom-node method [16], extended-finite element method (X-FEM) [17] and augmented-finite element method (A-FEM) [18, $19]$ to simulate progressive arbitrary failure in composite materials can yield more accurate results than numerical methods considering reducing the material properties to zero at the time of failure and turning the element's load carrying capacity off, the objective of the present work is to investigate the progressive degradation, delamination behavior, and strength of an open-hole AS4/PEEK laminate with the stochastic distribution of material properties using a three-dimensional numerical simulation. The cohesive elements technique proposed by Camanho and Dávila [20] are considered between two adjacent layers to model the failure due to delamination. The progressive intra-laminar damage model based on the sudden degradation rule is compared to the other approaches with strain-based continuum damage formulation proposed by Linde et al. [21]. The procedure of the progressive interand intra-laminar damage evolution is implemented in commercial software ABAQUS ${ }^{\text {TM }}$ [22] using programming in UMAT (user-defined material) subroutine. 


\section{Progressive damage models}

In order to establish a progressive damage analysis, a set of failure criteria and material property degradation rules are required. The failure criteria must properly take into account the damage mechanisms such as fiber breakage, matrix cracking, fiber/matrix shearing and delamination. In the following sections, different failure methods used in the current work are explained in details. Two methods (Method I and Method II) are according to the strain and stressbased continuum damage mechanics formulation. These methods consider the gradual material property degradation controlled by the individual fracture energies in both the fiber and the matrix. The onset of damage initiation in Method II is based on the Hashin failure criteria while the one in Method I is based on an exponential damage initiation law (a strain-based evolution approach) developed by Linde et al. [21]. However, the damage evolution in Method II is stress-based and incorporates a modification of Method I proposed by the authors of the present work. The third method (Method III) is based on Hashin failure criteria [2] and takes into account the effect of sudden material degradation rule. Inter-laminar damage or delamination in Methods I and II are according to cohesive zone technique while Method III uses the Hashin failure criteria. The details of these methods are described in the following sections.

\subsection{Method I}

\subsubsection{Intra-laminar damage model}

The failure criteria of Method I is a strain-based continuum damage formulation with different failure criteria for matrix and fiber [21]. It takes into account the gradual degradation of the material controlled by the individual fracture energies of matrix and fiber. Matrix failure initiates if the failure index, $M F$, defined below in Equation (1), exceeds the transverse tensile failure strain, $\varepsilon_{\mathrm{T}}^{\mathrm{t}}$ :

$M F^{2}=\left[\frac{\varepsilon_{\mathrm{T}}^{\mathrm{t}}}{\varepsilon_{\mathrm{T}}^{\mathrm{c}}}\left(\varepsilon_{22}\right)^{2}+\left(\varepsilon_{\mathrm{T}}^{\mathrm{t}}-\frac{\left(\varepsilon_{22}\right)^{2}}{\varepsilon_{\mathrm{T}}^{\mathrm{c}}}\right) \varepsilon_{22}+\left(\frac{\varepsilon_{\mathrm{T}}^{\mathrm{t}}}{\varepsilon_{\mathrm{s}}}\right)^{2}\left(\varepsilon_{12}\right)^{2}\right]>\left(\varepsilon_{\mathrm{T}}^{\mathrm{t}}\right)^{2}$

where $\varepsilon_{\mathrm{T}}^{\mathrm{c}}$ and $\varepsilon_{\mathrm{S}}$ represent the transverse compressive failure strain and the shear failure strain, respectively. $\varepsilon_{22}$ and $\varepsilon_{12}$ are the strain components perpendicular to fiber direction and shear direction, respectively. The matrix failure strains can be obtained from the following expressions shown as Equation (2):

$\varepsilon_{\mathrm{T}}^{\mathrm{t}}=\frac{Y_{\mathrm{t}}}{E_{22}} ; \quad \varepsilon_{\mathrm{T}}^{\mathrm{c}}=\frac{Y_{\mathrm{c}}}{E_{22}} ; \quad \varepsilon_{\mathrm{s}}=\frac{S_{12}}{E_{12}}$

where $E_{22}$ and $E_{12}$ are the undamaged laminate's transverse and shear stiffness, respectively. $Y_{\mathrm{t}}$ and $Y_{\mathrm{c}}$ represent transverse tensile and compressive failure strength, respectively. The shear failure strength is $S_{12}$.

Damage evolution variable, $d_{\mathrm{m}}$, is a function of the strain at failure, undamaged material stiffness, and the current value of the failure initiation variable. Also considered in the damage variable calculations are the fiber and matrix fracture energies $\left(G_{\mathrm{f}}\right.$ and $\left.G_{\mathrm{m}}\right)$ and the element characteristic length $\left(L_{\mathrm{c}}\right)$ to reduce the mesh sensitivity of the numerical model. The matrix damage, $d_{\mathrm{m}}$, takes place in the direction perpendicular to the fibers, and the fiber damage, $d_{\mathrm{f}}$, occurs in the direction parallel to the fibers. The matrix damage evolution parameter, $d_{\mathrm{m}}$, is calculated by Equation (3) [21]:

$d_{\mathrm{m}}=1-\frac{\varepsilon_{\mathrm{T}}^{\mathrm{t}}}{M F} \mathrm{e}^{\left[\mathrm{C}_{22} \varepsilon_{\mathrm{T}}^{\mathrm{t}}\left(\mathrm{MF}-\varepsilon_{\mathrm{T}}^{\mathrm{t}}\right) \mathrm{L}_{\mathrm{d}} / \mathrm{G}_{\mathrm{m}}\right]}$

where $C_{22}$ is the stiffness matrix component in the direction perpendicular to that of the fibers.

The fiber failure, $F F$, initiates if the following criterion defined by Equation (4) [21]:

$F F^{2}=\left[\frac{\varepsilon_{\mathrm{L}}^{\mathrm{t}}}{\varepsilon_{\mathrm{L}}^{\mathrm{c}}}\left(\varepsilon_{11}\right)^{2}+\left(\varepsilon_{\mathrm{L}}^{\mathrm{t}}-\frac{\left(\varepsilon_{11}\right)^{2}}{\varepsilon_{\mathrm{L}}^{\mathrm{c}}}\right) \varepsilon_{11}\right]>\left(\varepsilon_{\mathrm{L}}^{\mathrm{t}}\right)^{2}$

where $\varepsilon_{\mathrm{L}}^{\mathrm{c}}$ and $\varepsilon_{\mathrm{L}}^{\mathrm{c}}$ are longitudinal tensile and compressive failure strain, respectively and $\varepsilon_{11}$ is the longitudinal strain component.

The fiber failure strains can be obtained from Equation (5):

$\varepsilon_{\mathrm{L}}^{\mathrm{t}}=\frac{X_{\mathrm{t}}}{E_{11}}, \quad \varepsilon_{\mathrm{L}}^{\mathrm{c}}=\frac{X_{\mathrm{c}}}{E_{11}}$

where $E_{11}$ is the initial laminate's longitudinal stiffness. $X_{\mathrm{t}}$ and $X_{\mathrm{c}}$ represent longitudinal tensile and compressive failure strength, respectively.

Once Equation (4) is satisfied, the fiber damage parameter $d_{\mathrm{f}}$ evolves as shown in Equation (6) [21]:

$d_{\mathrm{f}}=1-\frac{\varepsilon_{\mathrm{L}}^{\mathrm{t}}}{F F} \mathrm{e}^{\left[\mathrm{C}_{11} \varepsilon_{\mathrm{L}}^{\left.\mathrm{t}\left(F F-\varepsilon_{\perp}^{\mathrm{t}}\right) \mathrm{L}_{\mathrm{c}} / \mathrm{G}_{\mathrm{t}}\right]}\right.}$

where $C_{11}$ is the component of stiffness matrix. 
Once damage initiates in the laminate, the laminates' stiffness degrades. Considering fiber and matrix damage evolution and transverse isotropy, the laminate's stiffness matrix is written as shown by Equation (7) [21]:

$$
\begin{gathered}
\left(1-d_{\mathrm{f}}\right) C_{13} \\
\left(1-d_{\mathrm{f}}\right)\left(1-d_{\mathrm{m}}\right) C_{23} \\
C_{33}
\end{gathered}
$$$$
\text { symmetry }
$$

where

$$
\begin{aligned}
& C_{11}=\frac{1-\nu_{23}^{2}}{E_{22} E_{33} \Delta} ; \quad C_{22}=\frac{1-\nu_{13} \nu_{31}}{E_{22} E_{11} \Delta} ; \quad C_{33}=C_{22} ; \\
& C_{12}=\frac{\nu_{12}+\nu_{32} \nu_{13}}{E_{22} E_{11} \Delta} ; \quad C_{13}=\frac{\nu_{13}+\nu_{23} \nu_{12}}{E_{22} E_{11} \Delta} ; \\
& C_{23}=\frac{\nu_{23}+\nu_{21} \nu_{13}}{E_{22} E_{11} \Delta} ; \quad C_{44}=E_{23} ; \quad C_{55}=E_{13} ; \\
& C_{66}=E_{12} ; \quad \Delta=\frac{1-\nu_{23}^{2}-\nu_{13} \nu_{31}-2 \nu_{21} \nu_{32} \nu_{13}}{E_{11} E_{22} E_{33}}
\end{aligned}
$$

where $v_{\mathrm{ij}}(i, j=1,2,3)$ is the Poisson ratio.

The damage growth reduces the stiffness and consequently the stress tends to redistribute in each element of the material.

\subsubsection{Inter-laminar damage (delamination) model}

Inter-laminar damage is simulated by placing cohesive elements between two adjacent layers. The constitutive response of the cohesive elements is described by a linear traction-separation law as presented in Figure 1. Figure 1 shows the schematic of material response in normal, shear and mixed mode loading. The triangles in the two vertical coordinate planes $\left(\left(\sigma, \delta_{\mathrm{I}}\right)\right.$ and $\left(\sigma, \delta_{\text {Shear }}\right)$ planes $)$ represent the response under pure normal and pure shear deformation, respectively. The intermediate vertical plane $\left(\left(\sigma, \delta_{\mathrm{m}}\right)\right.$ plane $)$ represents the damage response under mixed mode condition. This figure shows that the material response is linear until it reaches a peak value of stress after which it softens linearly in the post-peak region. The initiation under different modes of pure normal $\left(\delta_{\mathrm{I}}^{0}\right)$, pure shear $\left(\delta_{\text {Shear }}^{0}\right)$ and mixed mode loading $\left(\delta_{\mathrm{m}}^{0}\right)$ occurs when the interlaminar stress reaches the inter-laminar pure normal

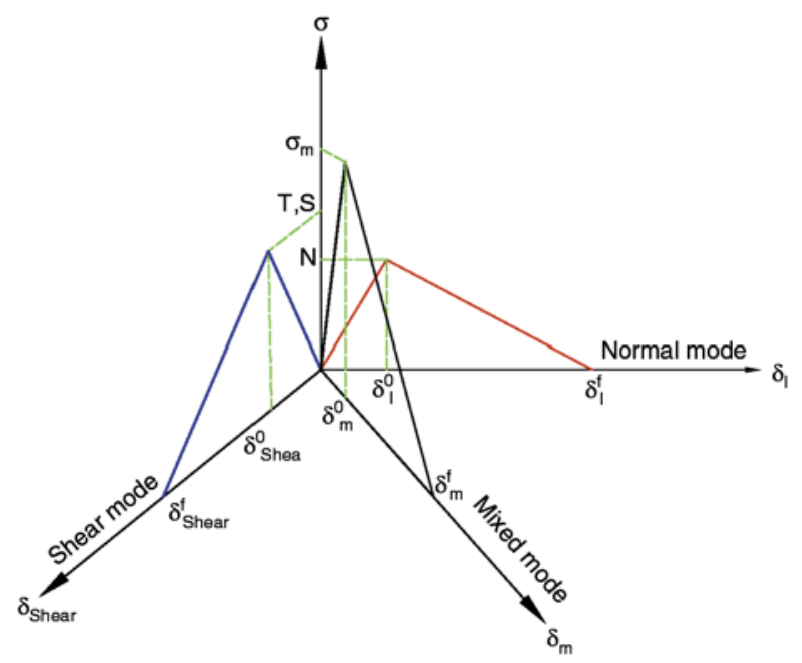

Figure 1. Schematic of bilinear constitutive behavior of cohesive zone for different modes of failure

strength $\left(\sigma_{\mathrm{I}}\right)$, pure shear strength $\left(\sigma_{\text {Shear }}\right)$, or mixed mode strength $\left(\sigma_{\mathrm{m}}\right)$ depending on the mode of the loading. The growth regime represents the softening and separation behavior of the degraded material's element. The material's element is completely delaminated once the area under traction-displacement (Figure 1) reaches the fracture energy, $G_{\mathrm{c}}$, and the failure displacement, $\sigma_{\mathrm{m}}^{\mathrm{f}}$, is reached. The cohesive elements and their constitutive responses are programmed in ABAQUS ${ }^{\mathrm{TM}}$ for the prediction of delamination initiation and propagation. A high initial stiffness (the so-called penalty stiffness; $K_{\mathrm{p}}$ ) is defined to avoid de-cohesion of two surfaces in the linear elastic range.

\section{Delamination initiation:}

The onset of delamination initiation is determined based on a quadratic nominal strain criterion [22]. The strength of the adhesive in the normal and shear directions are used as input data, as shown by Equation (8): 
$\left(\frac{\varepsilon_{\mathrm{n}}}{\varepsilon_{\mathrm{n}}^{\mathrm{f}}}\right)^{2}+\left(\frac{\varepsilon_{\mathrm{s}}}{\varepsilon_{\mathrm{s}}^{\mathrm{f}}}\right)^{2}+\left(\frac{\varepsilon_{\mathrm{t}}}{\varepsilon_{\mathrm{s}}^{\mathrm{f}}}\right)^{2}>1$ with $\quad \varepsilon_{\mathrm{n}}^{\mathrm{f}}=\frac{N}{K_{\mathrm{p}}}$

$\varepsilon_{\mathrm{s}}^{\mathrm{f}}=\frac{S}{K_{\mathrm{p}}}=\frac{T}{K_{\mathrm{p}}}$

where $\varepsilon_{\mathrm{n}}^{\mathrm{f}}, \varepsilon_{\mathrm{s}}^{\mathrm{f}}$ are inter-laminar tensile and shear strain. $\varepsilon_{\mathrm{s}}$ is tensile strain component, $\varepsilon_{\mathrm{s}}$ and $\varepsilon_{\mathrm{t}}$ are shear strain component. Parameter $N$ is the inter-laminar tensile strength; $S$ and $T$ represent the inter-laminar shear strength. It is noted that for convenience, we considered a constitutive thickness of $1.0 \mathrm{~mm}$ such that there is no need to distinguish between the nominal strain and the separation displacement in the above equation.

\section{Delamination growth:}

The damage evolution or delamination propagation law postulates that the material stiffness is degraded once the corresponding initiation criterion is met. The damage propagation prediction is usually studied in terms of energy release rate and fracture toughness. Mixed-mode delamination growth is predicted when mixed mode fracture energy $\left(G_{\mathrm{T}}\right)$ is greater than critical fracture energy $\left(G_{\mathrm{C}}\right)$. Several laws implemented in FEM codes have been considered to compute the fracture toughness for mixedmode failure, such as Benzeggagh-Kenane (B-K) criterion [23] the power law criterion [24], and the Reeder criterion [25]. Demonstration of applications of B-K criterion can be found in the work of Camanho et al. [26] for PEEK and epoxy composites. In this study, the 'power law criterion' proposed by Benzeggagh-Kenane - the so-called B-K criterion - [23] is used. This criterion is established in terms of an interaction between the energy release rates to predict the delamination evolution as shown by Equation (9):

$$
\begin{aligned}
& G_{\text {Ic }}+\left(G_{\text {IIc }}-G_{\text {Ic }}\right)\left(\frac{G_{\text {II }}+G_{\text {III }}}{G_{\mathrm{T}}}\right)^{\eta}=G_{\mathrm{c}}, \text { with } \\
& T=G_{\mathrm{I}}+G_{\mathrm{II}}+G_{\mathrm{III}}
\end{aligned}
$$

where $\eta$ is a material parameter and $G_{\text {Ic }}$ and $G_{\text {IIc }}$ are the fracture energies of Mode I and II at failure, respectively. $G_{\mathrm{c}}$ is critical fracture energy. $G_{\mathrm{I}}, G_{\mathrm{II}}$ and $G_{\mathrm{III}}$ are fracture energies of Mode I, II, and III.

\subsection{Method II}

Method II is the modified of Method I and is a stressbased continuum damage formulation with the fiber and matrix failure proposed by the present authors. The main difference between Methods I and II is in the definition of matrix and fiber failure indices $(M F$ and $F F)$ in which the former uses the strainbased approach and the latter II uses the stressbased approach. Damage initiation is based on the Hashin failure criteria summarized in Table 1.

As summarized in Table 1, seven sets of initiation criteria are considered. For detecting fiber, matrix and delamination some indices are defined, i.e., $M F$ for matrix failure in either tension or compression, $F F$ for fiber failure in either tension or compression, $D E L T$ delamination failure in tension and DELC for delamination failure in compression. Once each of the indices reaches the unit value, failure is initiated and softening process in the material begins.

The matrix damage evolution parameter $d_{\mathrm{m}}$ is the modified version of Equation (3) and based on stress approach described by Equation (10) (Please see Section 2.1. for more details):

$d_{\mathrm{m}}=1-\frac{Y_{\mathrm{t}}}{E_{22} M F} \mathrm{e}^{\left[\mathrm{Y}_{\mathrm{t}}\left(\mathrm{MF}-\frac{\mathrm{Y}_{\mathrm{t}}}{\varepsilon_{22}}\right) \mathrm{L}_{\mathrm{c}} / \mathrm{G}_{\mathrm{m}}\right]}$

The fiber damage evolution $d_{\mathrm{f}}$ is obtained using Equation (11):

$d_{\mathrm{f}}=1-\frac{X_{\mathrm{t}}}{E_{11} F F} \mathrm{e}^{\left[\mathrm{X}_{\mathrm{t}}\left(\mathrm{FF}-\frac{\mathrm{X}_{\mathrm{t}}}{\mathrm{E}_{11}}\right) \mathrm{L}_{\mathrm{d}} / \mathrm{G}_{\mathrm{f}}\right]}$

The procedure for evaluation of delamination or inter-laminar damage is the same as the delamination method described in Section 2.1.2. (Please see Section 2.1 for more details).

\subsection{Method III}

Method III uses the Hashin failure criteria as summarized in Table 1. This method is used for identifying matrix tensile/compressive cracking, fiber tensile/compressive breakage, fiber/matrix shear failure, and tension/compression delamination. If failure criterion is satisfied in an element, the material properties of that failed element is changed by a set of material properties in accordance with the sudden degradation rule. Corresponding to the type of the failure, the laminate response against the load is changed in the case of the damage. The sudden stiff- 
Table 1. Hashin failure criteria and material degradation rules $[2,3,15]$

\begin{tabular}{|l|l|l|l|}
\hline \multicolumn{1}{|c|}{ Failure mode } & \multicolumn{1}{|c|}{ Failure index } & Failure approach & \multicolumn{1}{c|}{$\begin{array}{c}\text { Material degradation rule } \\
\text { (for Method III) }\end{array}$} \\
\hline $\begin{array}{l}\text { Matrix tensile failure } \\
\left(\sigma_{22}>0\right)\end{array}$ & $M F^{2}=\left(\frac{\sigma_{22}}{Y_{\mathrm{t}}}\right)^{2}+\left(\frac{\sigma_{12}}{S_{12}}\right)^{2}+\left(\frac{\sigma_{23}}{S_{23}}\right)^{2}>1$ & Method II and III & $\begin{array}{l}E_{22} \rightarrow 0.2 E_{22}, E_{12} \rightarrow 0.2 E_{12}, \\
E_{23} \rightarrow 0.2 E_{23}\end{array}$ \\
\hline $\begin{array}{l}\text { Matrix compression failure } \\
\left(\sigma_{22}<0\right)\end{array}$ & $M F^{2}=\left(\frac{\sigma_{22}}{Y_{\mathrm{c}}}\right)^{2}+\left(\frac{\sigma_{12}}{S_{12}}\right)^{2}+\left(\frac{\sigma_{23}}{S_{23}}\right)^{2}>1$ & Method II and III & $\begin{array}{l}E_{22} \rightarrow 0.4 E_{22}, E_{12} \rightarrow 0.4 E_{12}, \\
E_{23} \rightarrow 0.4 E_{23}\end{array}$ \\
\hline $\begin{array}{l}\text { Fiber tensile failure } \\
\left(\sigma_{11}>0\right)\end{array}$ & $F F^{2}=\left(\frac{\sigma_{11}}{X_{\mathrm{t}}}\right)^{2}+\left(\frac{\sigma_{12}}{S_{12}}\right)^{2}+\left(\frac{\sigma_{13}}{S_{13}}\right)^{2}>1$ & Method II and III & $E_{11} \rightarrow 0.07 E_{11}$ \\
\hline $\begin{array}{l}\text { Fiber compression failure } \\
\left(\sigma_{11}<0\right)\end{array}$ & $F F^{2}=\left(\frac{\sigma_{11}}{X_{\mathrm{c}}}\right)^{2}+\left(\frac{\sigma_{11}}{X_{\mathrm{c}}}\right)^{2}>1$ & Method II and III & $E_{11} \rightarrow 0.14 E_{11}$ \\
\hline $\left.\begin{array}{l}\text { Fiber/matrix shear failure } \\
S_{12}\end{array}\right)^{2}\left(\frac{\sigma_{13}}{S_{13}}\right)^{2}>1$ & Method III & $E_{11} \rightarrow 0$ \\
\hline $\begin{array}{l}\text { Inter-laminar tensile failure } \\
\left(\sigma_{33}>0\right)\end{array}$ & $D E L T^{2}=\left(\frac{\sigma_{33}}{Z_{\mathrm{t}}}\right)^{2}+\left(\frac{\sigma_{13}}{S_{13}}\right)^{2}+\left(\frac{\sigma_{23}}{S_{23}}\right)^{2}>1$ & Method III & $E_{33}, E_{23}, E_{13}, \rightarrow 0$ \\
\hline $\begin{array}{l}\text { Inter-laminar compression failure } \\
\left(\sigma_{33}>0\right)\end{array}$ & $D E L C^{2}=\left(\frac{\sigma_{33}}{Z_{\mathrm{c}}}\right)^{2}+\left(\frac{\sigma_{13}}{S_{13}}\right)^{2}+\left(\frac{\sigma_{23}}{S_{23}}\right)^{2}>1$ & Method III & $E_{33}, E_{23}, E_{13}, \rightarrow 0$ \\
\hline
\end{tabular}

ness degradation of the failed element in the matrix and fibers is different. For example, once the matrix fails in tension, the transverse stiffness, $E_{22}$, drops to $0.2 E_{22}$ while at the onset of the fiber failure the longitudinal stiffness, $E_{11}$, reduces to $0.07 E_{11}$. Therefore, in the current work, the material degradation rules are based on the work of $[27,28]$ for matrix tensile/compressive failure and for fiber tensile/compressive failure (See Table 1). Note that fiber/matrix shear and delamination failure were not considered in the work of $[27,28]$ and therefore material property is reduced to a small value for these damage modes.

\section{Model development}

To perform stress and progressive damage analysis based on Methods I, II, III, a three-dimensional finite element model is created in ABAQUSTM [22]. One end of the laminate is clamped in $\mathrm{x}, \mathrm{y}$, and $\mathrm{z}$ and the other end is subjected to the uniform displacement of $v$ (Figure 2a). ABAQUS 6-node linear triangular prism (C3D6) is defined to mesh the composite laminate such that each ply has one element through the thickness direction. ABAQUS 6-node, three-dimensional cohesive element (COH3D6) is defined to mesh the cohesive layers with $0.001 \mathrm{~mm}$ thickness. Two types of laminates configuration are considered in the model. The first one is $[0 / 60 /-45 /+45]_{3 \mathrm{~s}}$ described in details in Section 5. The second one is
Table 2. Mesh specifications of the model

\begin{tabular}{|l|c|c|}
\hline & $\begin{array}{c}\text { Number of } \\
\text { elements }\end{array}$ & $\begin{array}{c}\text { Average aspect } \\
\text { ratio }\end{array}$ \\
\hline Mesh 1 & 8937 & 2.45 \\
\hline Mesh 2 & 24854 & 1.7 \\
\hline Mesh 3 & 54374 & 1.4 \\
\hline
\end{tabular}

$[0 / 45 / 90 /-45]_{2 \mathrm{~s}}$ for which experimental data and numerical results are available in [7]. The latter is chosen to verify the results of the presented simulation; See Table 2. In each case, because of the symmetry condition, only one quarter of the specimen is modeled. That is, the model is in the shape of the specimen is cut in half in $X Z$ plane and then cut in half in $Y Z$ plane. Boundary conditions are shown in Figure 2a.

\subsection{Stochastic material properties distribution}

The laminate's stiffness and strength are generated using the Gaussian distribution function with around $\pm 1 \%$ of variation to consider spatial stochastic properties in the model. A typical Gaussian distribution of the AS4/PEEK longitudinal stiffness is shown in Figure 2b. Gaussian distribution function is defined in user-subroutine SDVINI in ABAQUS which enables the user to specify the initial solution-dependent state variables with stochastic material properties. 


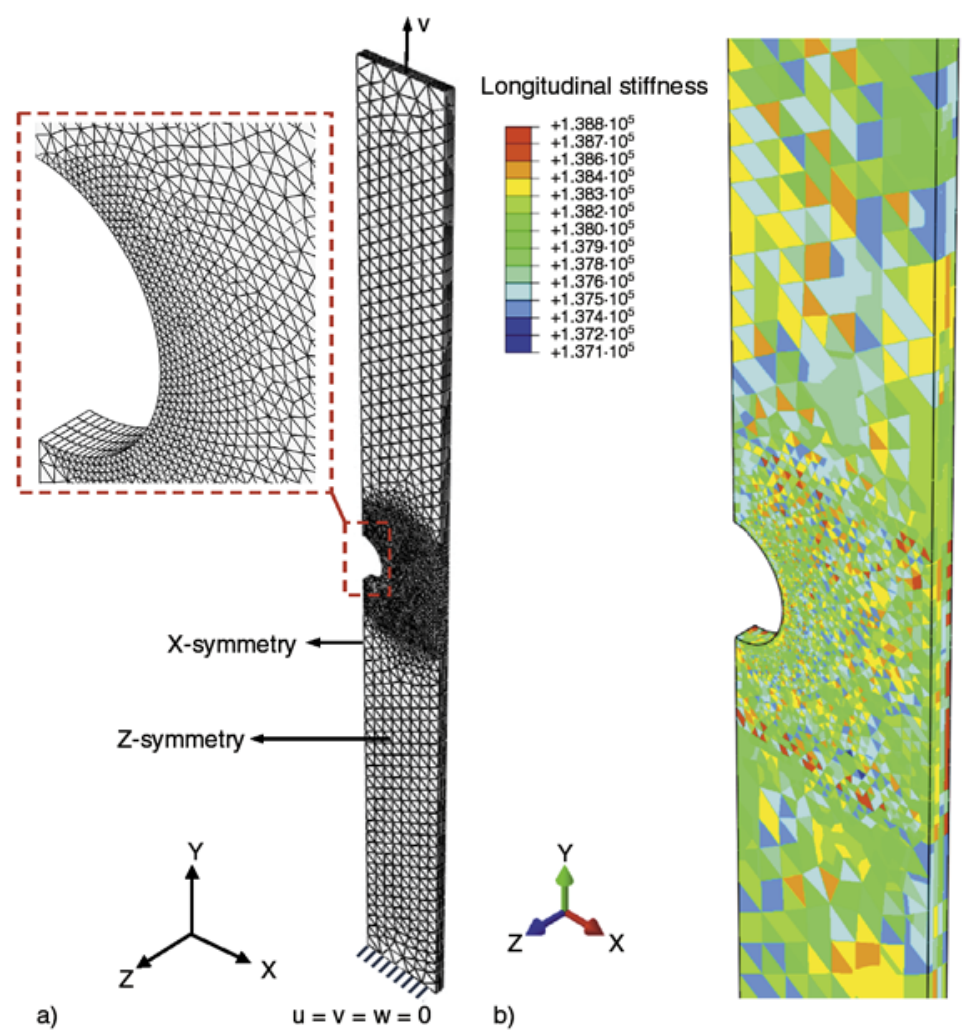

Figure 2. (a) 3D Finite element mesh and boundary conditions, (b) Gaussian distribution of longitudinal stiffness

\subsection{Numerical procedure}

The progressive damage model is implemented in ABAQUS ${ }^{\mathrm{TM}}$ through the user-defined subroutine UMAT to describe the specific material characteristics. This subroutine is called to determine the material properties at each point. The stresses and solution-dependent state variables are updated at the end of each iteration and the Jacobian matrix is recalculated accordingly. The simulation starts with the model preparation as presented in the flowchart of the procedure; See Figure 3. Then, a Gaussian distribution for the laminate properties is applied to all the elements. Stress analysis is then performed based on the applied displacement followed by the failure analysis. The values of the failure indexes are stored as the solution-dependent state variables. If the damage initiation criterion is satisfied, damage evolution laws are applied for Methods I and II. In Method III, if the damage initiation criterion is met, the material properties are treated according to the sudden material degradation rule. If there is no failure, an incremental displacement, $\delta v$, is added to the last displacement amplitude, $v_{\mathrm{i}}$. Next, a new Jacobian is computed, the stress is redistributed accordingly, and the calculations are repeated. The failure occurs when the laminate cannot tolerate any more load increment. Physically, this represents a large deflection and excessive damage at which point the program is terminated. Program is stopped at this stage and simulation cannot pass any new increment. It is noted that the case in which there is no failure does not have any inconsistency with equilibrium solution and new increment successfully run.

\section{Sensitivity analysis parameters}

Sensitivity studies are performed to examine the influence of various parameters on the load-displacement curves of the progressive damage models. The parameters of particular interest pertain to mesh density and viscous regularization $(\mu)$.

\section{Mesh dependency:}

The problem of strain localization induced by damage localization is treated by a method that minimizes the mesh dependency in the numerical results. This is done by using the fracture energy-based damage evolution and considering the characteristic length of the element into the damage evolution law. The calculation of the characteristic length without considering the crack direction depends on the element geometry and formulations. Hence, the problem of mesh dependency still exists [13]. In order to minimize the problem of mesh dependency, elements' aspect ratio (the ratio of shortest edge to the 


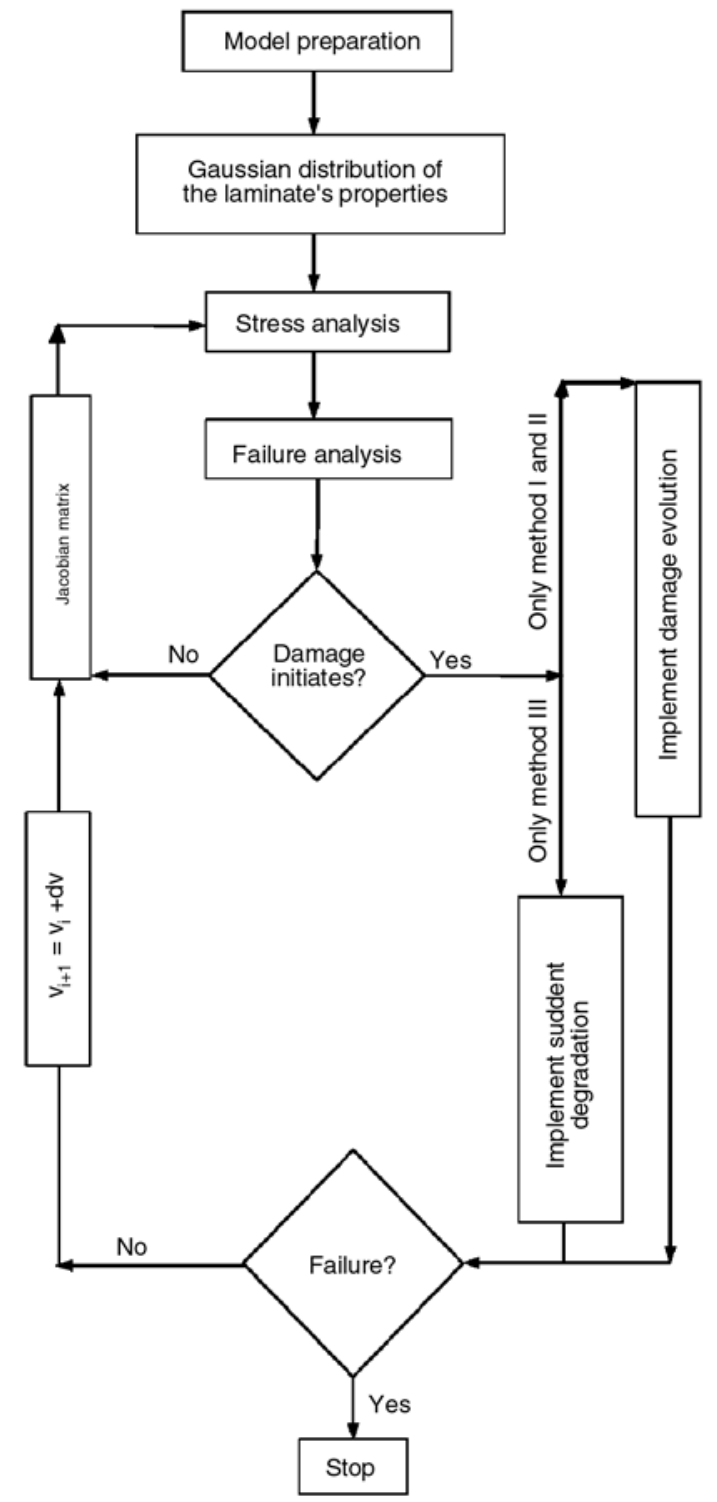

Figure 3. Damage flowchart implemented in ABAQUSTM

longest edge of an element) should be close to one. The results of three different mesh refinements are summarized in Table 2.

\section{Viscous regularization factor $(\mu)$ :}

Material models that exhibits softening behavior and stiffness degradation often tend to have severe convergence difficulties. A common technique to alleviate the associated convergence difficulties is to implement the so-called viscous regularization factor which through the introduction of a viscosity term in the damage evolution of Equations (10) and (11) forces the tangent stiffness matrix of the softening material to be positive definite for adequately small time increments $[9,22]$. It is important to check that the energy associated with viscous regularization is small compared to the overall strain energy. The time evolution equation of viscous damage variable is as defined by Equations (12) and (13) $[9,22]$ :

$\dot{d}_{\mathrm{m}}^{\mathrm{v}}=\frac{1}{\mu}\left(d_{\mathrm{m}}-d_{\mathrm{m}}^{\mathrm{v}}\right)$

$\dot{d}_{\mathrm{f}}^{\mathrm{v}}=\frac{1}{\mu}\left(d_{\mathrm{f}}-d_{\mathrm{f}}^{\mathrm{v}}\right)$

where $d_{\mathrm{m}}^{\mathrm{v}}$ and $d_{\mathrm{f}}^{\mathrm{v}}$ are the regularized matrix and fiber damage variables used in the calculation of damage stiffness matrix and Jacobian matrix, respectively.

\section{Material and experiment}

The material of the present work is an AS4/PEEK quasi-isotropic laminate $[0 / 90 /-45 /+45]_{3 \mathrm{~s}}$ with polyether-ether-ketone matrix and carbon fiber and fabricated using the autoclave method from the prepreg (APC-2). The volume fraction of the fibers is $60 \%$ according to the data provided by the manufacturer. The specimens are prepared according to ASTM D3039M with a centrally circular hole. The specimen dimensions and mechanical properties of AS4/PEEK laminate are summarized in Table 3 and Table 4, respectively. As presented in Table 3, $L$ is the length of specimen, $W$ is the width and $D$ is the hole diameter. Fracture properties are summarized in Table 5 [29] and the values of fracture energies of the fiber and matrix in Table 5 are from [9]. Static tests were performed on a universal fatigue test

Table 3. The laminate dimensions

\begin{tabular}{|c|c|c|c|c|}
\hline $\begin{array}{c}\text { Laminate } \\
\text { configuration }\end{array}$ & $\begin{array}{c}\mathbf{L} \\
{[\mathbf{m m}]}\end{array}$ & $\begin{array}{c}\mathbf{W} \\
{[\mathbf{m m}]}\end{array}$ & $\begin{array}{c}\mathbf{D} \\
{[\mathbf{m m}]}\end{array}$ & $\begin{array}{c}\text { Thickness } \\
\text { of each layer } \\
{[\mathbf{m m}]}\end{array}$ \\
\hline$[0 / 90 /-45 /+45]_{3 \mathrm{~s}}$ & 254 & 25.4 & 6.35 & 0.139 \\
\hline$[0 /+45 / 90 /-45]_{2 \mathrm{~s}}$ & 100 & 20 & 5 & 0.125 \\
\hline
\end{tabular}

Table 4. Material properties of AS4/PEEK

\begin{tabular}{|l|c|}
\hline \multicolumn{1}{|c|}{ Material properties } & AS4/PEEK \\
\hline$E_{11}[\mathrm{GPa}]$ & 138 \\
$E_{22}=E_{33}[\mathrm{GPa}]$ & 10.2 \\
$E_{12}=E_{13}[\mathrm{GPa}]$ & 5.7 \\
$E_{23}$ & 3.7 \\
$v_{12}=v_{13}$ & 0.3 \\
$v_{23}$ & 0.45 \\
\hline$X_{\mathrm{t}}[\mathrm{MPa}]$ & 2070 \\
$X_{\mathrm{c}}[\mathrm{MPa}]$ & 1360 \\
$Y_{\mathrm{t}}=Z_{\mathrm{t}}[\mathrm{MPa}]$ & 86 \\
$Y_{\mathrm{c}}=Z_{\mathrm{c}}[\mathrm{MPa}]$ & 230 \\
$S_{12}=S_{13}[\mathrm{MPa}]$ & 186 \\
$S_{23}[\mathrm{MPa}]$ & 86 \\
\hline
\end{tabular}


Table 5. Fracture properties of AS4/PEEK laminate

\begin{tabular}{|c|c|c|c|c|c|c|c|}
\hline $\begin{array}{c}\mathbf{G}_{\text {Ic }} \\
{[\mathbf{N} / \mathbf{m m}]}\end{array}$ & $\begin{array}{c}\mathbf{G}_{\text {IIc }}=\mathbf{G}_{\text {IIIc }} \\
{[\mathbf{N} / \mathbf{m m}]}\end{array}$ & $\begin{array}{c}\mathbf{N} \\
{[\mathbf{M P a}]}\end{array}$ & $\begin{array}{c}\mathbf{S}=\mathbf{T} \\
{[\mathbf{M P a}]}\end{array}$ & $\begin{array}{c}\mathbf{G}_{\mathbf{f}} \\
{[\mathbf{N} / \mathbf{m m}]}\end{array}$ & $\begin{array}{c}\mathbf{G}_{\mathbf{m}} \\
{[\mathbf{N} / \mathbf{m m}]}\end{array}$ & $\begin{array}{c}\mathbf{K}_{\mathbf{p}} \\
{[\mathbf{M P a} / \mathbf{m m}]}\end{array}$ \\
\hline 1.7 & 2 & 80 & 100 & 12.5 & 1.0 & 2.284 & $10^{6}$ \\
\hline
\end{tabular}

machine (TESTRESOURCES Model 930LX50T2000).

\section{Results and discussions}

Numerical results of the progressive damage analysis of two quasi-isotropic open-hole specimens with the laminates' configuration of $[0 / 90 /-45 /+45]_{3 \mathrm{~s}}$ and $[0 / 45 / 90 /-45]_{2 \mathrm{~s}}$ are presented in this section. First, degradation and failure analysis of the laminate with the configuration of $[0 / 45 / 90 /-45]_{2 \mathrm{~s}}$ is performed using the three different methods and compared to the numerical and experimental results of [7] to validate the model. Also presented are the results of the dependency of the present model to viscous regularization parameter and a mesh refinement study. Second, the predicted failure strength and damage of the laminate with the configuration of $[0 / 90 /-45 /+45]_{3 \mathrm{~s}}$ is compared to the experimental results.

\section{1. $[0 / 45 / 90 /-45]_{2 s}$ laminate}

Figure 4 shows the comparison of load-displacement curves of different progressive damage approaches (Method I, II, and III) with the experimental and numerical data of [7] for $[0 / 45 / 90 /-45]_{2 \mathrm{~s}}$ AS4/PEEK laminate. It shows that once the damage accumulation increases and the laminate is not able to sustain more load, the strength reduces and numerical simulation is stopped due to excessive element distortion. Three regions can be seen in

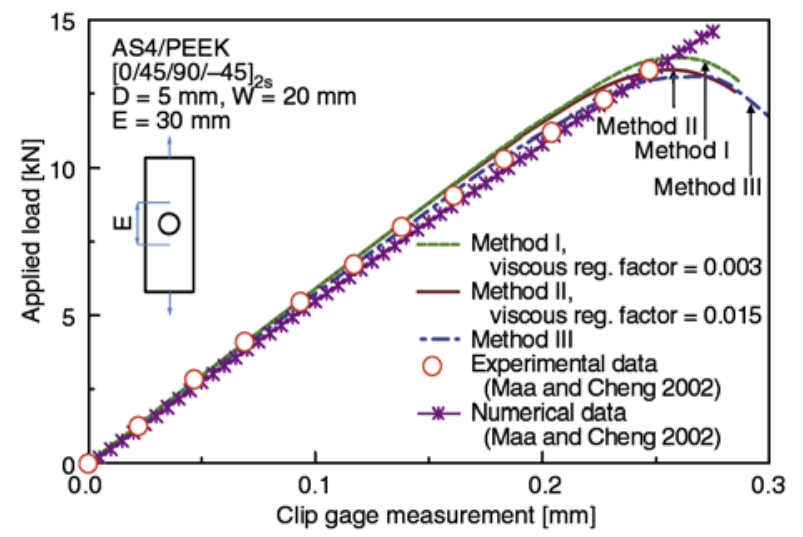

Figure 4. Comparison of predicted load-displacement curves of different progressive damage methods with the experimental and numerical data of [7] for $[0 / 45 / 90 /-45]_{2 s}$ AS4/PEEK laminate these curves: a linear response, softening trend representing the initiation and propagation of the damage such as fiber and matrix failure when damage occurs in critical number of elements, followed by a region in which the load capacity drops. Compared to the experimental and numerical data, the prediction of the current numerical simulations are quite close.

Mesh size study is performed to evaluate the effect of mesh density on the prediction of failure strength. Three different meshes ranges from a coarse (Mesh I), medium (Mesh II) to a fine (Mesh III) for the area around the hole are shown in Figure 5. The viscous regularization factor of 0.003 is used with the degradation analysis of Method I. It can be seen that for Mesh I the abrupt decrease of the ultimate strength is slightly greater than the experimental result and that it overestimates the failure strength by about 3 percent. By refining the mesh and reducing the aspect ratio of the meshes to close to 1 , the results of Mesh II and III predictions show close agreement with those obtained experimentally. Although the characteristic length is considered in the damage analysis to minimize the mesh size effect, a slight dependency to the mesh size still exists in the numerical results.

Figure 6 gives the load-displacement results of different values of the viscosity parameter in Methods I and II. It can be seen that the smaller the viscous regularization factor, the more abrupt the failure and the smaller failure strength become. Since two

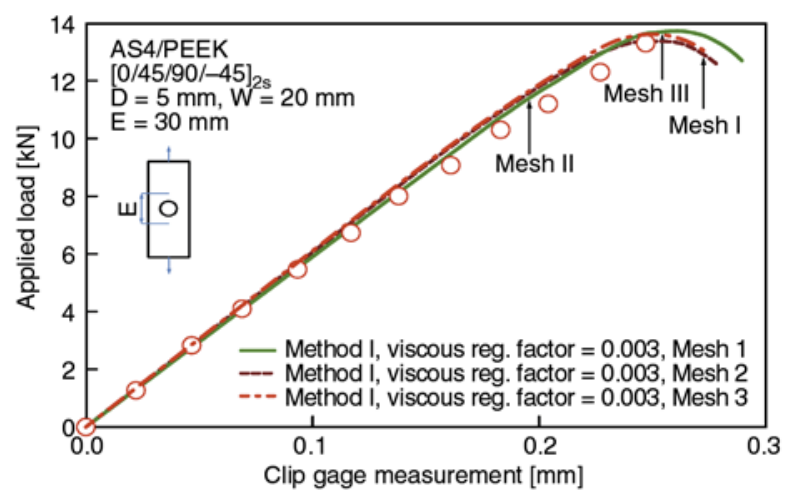

Figure 5. Comparison of load-displacement curves of different mesh sizes using Method I with the experimental data of [7] for [0/45/90/-45] $]_{2 \mathrm{~s}}$ AS4/PEEK laminate 


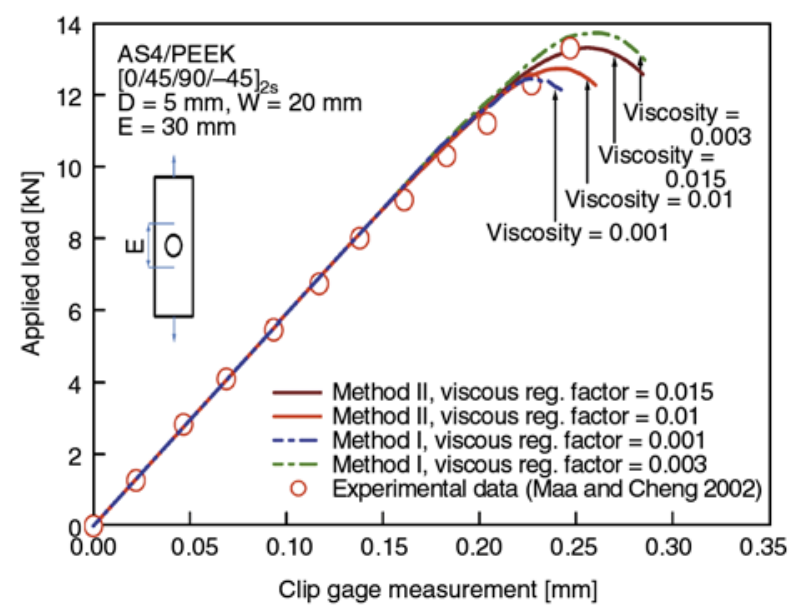

Figure 6. Comparison of predicted load-displacement curves of different values of viscosity parameters using Method I and II with the experimental data of [7] for $[0 / 45 / 90 /-45]_{2 \mathrm{~s}} \mathrm{AS} 4 / \mathrm{PEEK}$ laminate

approaches use different failure criteria, two different viscosity parameters are considered in the simulations. The intra-laminar damage initiation based on stress criteria seems to have higher viscosity factor than that of with strain criteria.

\section{2. $[0 / 90 /-45 /+45]_{3 \mathrm{~s}}$ laminate}

The comparison of load-displacement curves of different progressive damage approaches (Method I, II, and III) with the experiment for $[0 / 90 /-45 /+45]_{3 \mathrm{~s}}$ AS4/PEEK laminate is presented in Figure 7. The same viscous regularization factor as in the case of $[0 / 90 /-45 /+45]_{3 \mathrm{~s}}$ laminate is used for this simulation. The simulation results are consistent with the experimental results.

Figure 8 shows inter-laminar or delamination damage pattern at $0 / 90^{\circ}, 90 /-45^{\circ}$, and $-45 / 45^{\circ}$ interface of $[0 / 90 /-45 /+45]_{3 \mathrm{~s}}$ AS4/PEEK laminate at the time when the laminate strength start to drop. As shown in this figure, the delamination at $90 /-45^{\circ}$ and $-45 / 45^{\circ}$ interfaces are more severe than the delami-

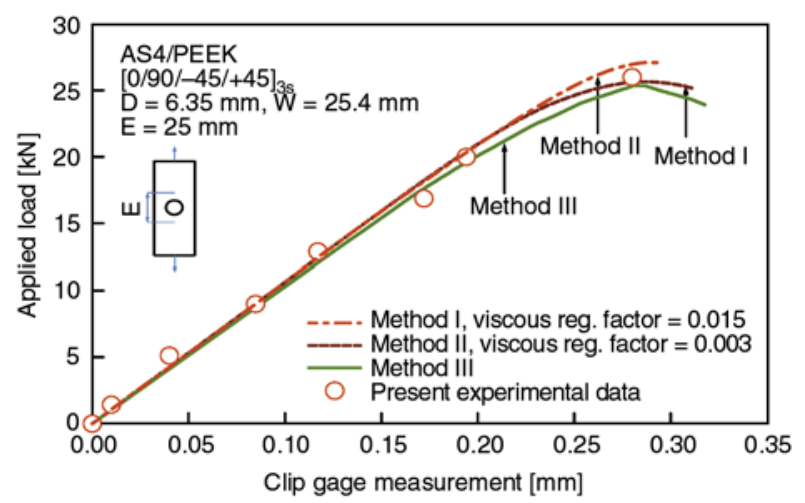

Figure 7. Comparison of predicted load-displacement curves of different progressive damage methods with the current experimental data of [7] for $[0 / 90 /-45 /+45]_{3 \mathrm{~s}}$ AS4/PEEK laminate

nation at $0 / 90^{\circ}$ interface. Since the dominant failure stress in $0 / 90^{\circ}$ interface is the normal stress, delamination pattern is in the zero degree direction. In the case of $90 /-45^{\circ}$ and $-45 / 45^{\circ}$ interface, the delamination patterns tend toward the $45^{\circ}$ failure direction.

A contour plot of fiber and matrix damage variables $d_{\mathrm{f}}$ and $d_{\mathrm{m}}$ defined in Equations (11) and (12) as well as the surfaces of the failed specimen for $[0 / 90 /$ $-45 /+45]_{3 s}$ AS4/PEEK laminate is shown in Figure 9. Figure 9 also shows how implementation of the stochastic in material properties changes the failure behavior and path of the laminate. As seen in Figures $9 \mathrm{a}-9 \mathrm{c}$ the intra-laminar damage of the $0^{\circ}$ fibers which are the most catastrophic failure types within the laminate initiates at the tip of the hole and propagates in the direction perpendicular to the load direction. In order to show the randomness behavior of failure due to probable distribution of the material properties, the scatter of the $0^{\circ}$ fiber failure path is obtained by re-running the model for three times (paths 1, 2, 3). In each run, the failure path differs in the direction perpendicular to the fiber directions. Comparing Figures $9 \mathrm{a}-9 \mathrm{c}$ with the

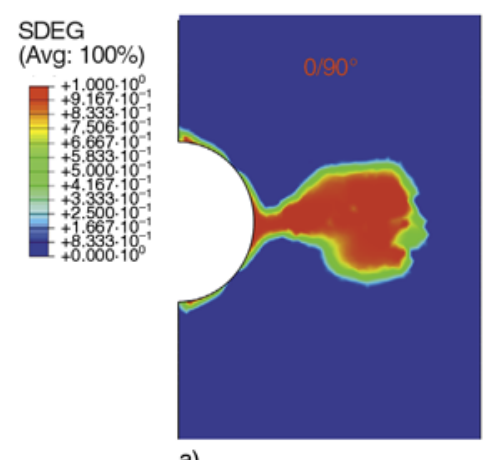

a)

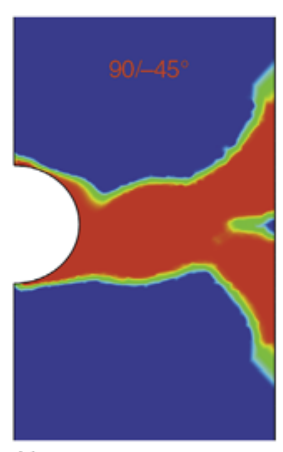

b)

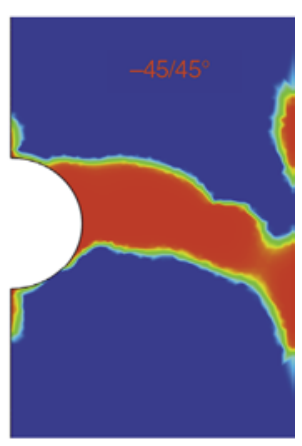

c)

Figure 8. Delamination failure at the interface of $0 / 90^{\circ}$ (a), $90 /-45^{\circ}$ (b), and $-45 / 45^{\circ}$ (c) for $[0 / 90 /-45 /+45]_{3 \mathrm{~s}}$ AS4/PEEK laminate using Method I 
image of failed specimen (Figure 9d), the results indicate that the failure of $0^{\circ}$ plies can be either in the direction perpendicular to the fibers or in the inclined direction depending on sub-critical damage development in the adjacent plies. The numerical failure paths in Figures $9 \mathrm{a}-9 \mathrm{c}$ are consistent with the image of the failed laminate. Figures 9e-9f show
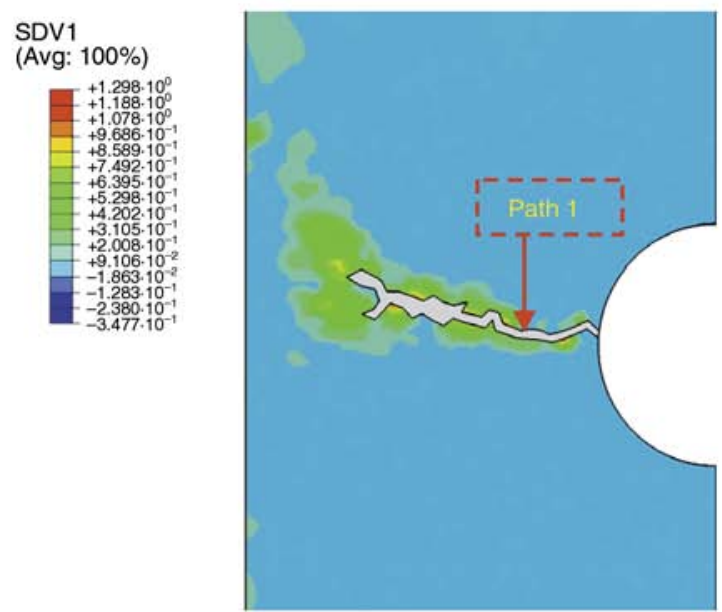

a) SDV1
(Avg: $100 \%)$
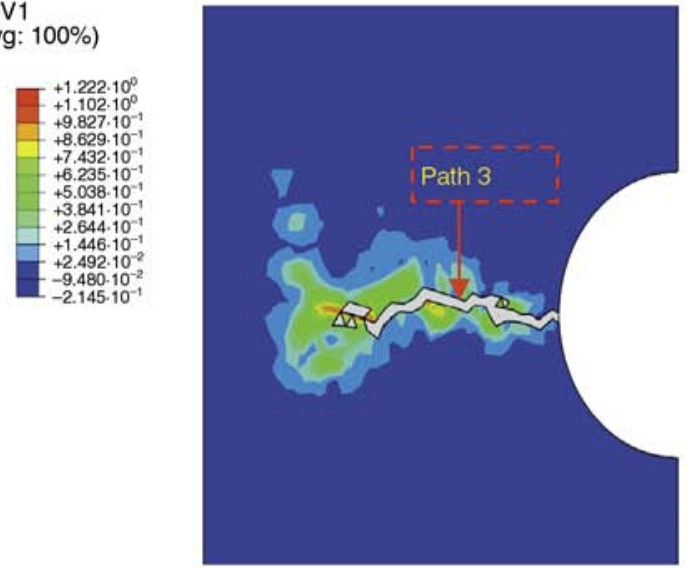

c)

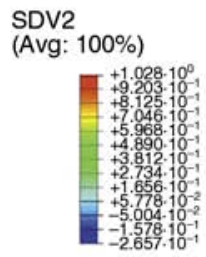

e)

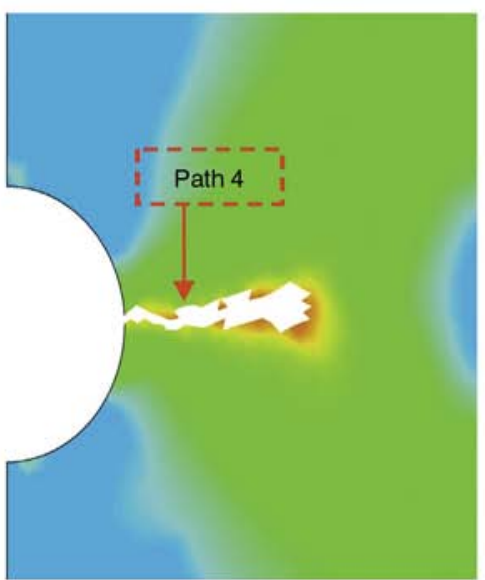

the damage patterns for matrix failure in 90 and $45^{\circ}$ plies, respectively. The matrix strength, $Y_{\mathrm{t}}$, is small compared to the fiber strength, $X_{\mathrm{t}}$, and matrix failure is the sever type of the damage in 90,45 , and $-45^{\circ}$ plies. As seen in Figures 9e-9f, the matrix failure path of 90 and $45^{\circ}$ plies is in the 0 and 45 directions, respectively (path 4,5 ).

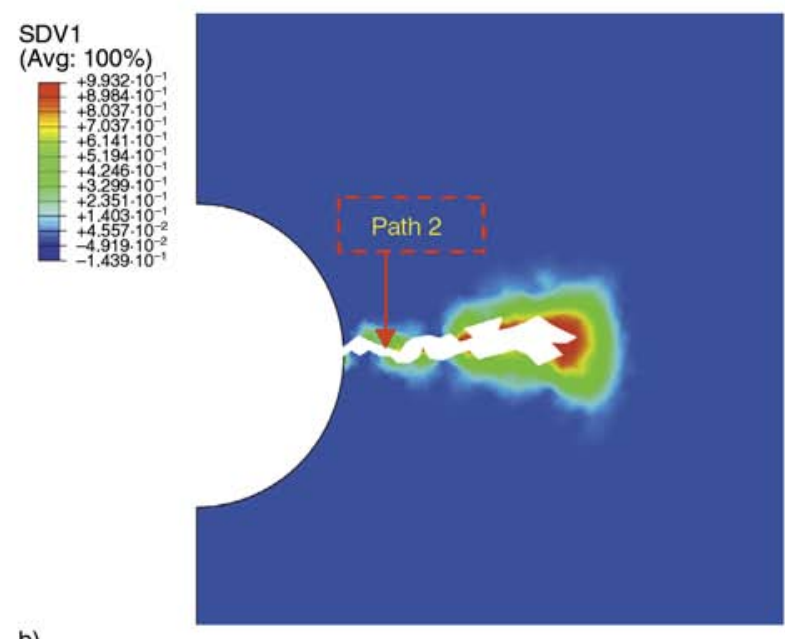

b)

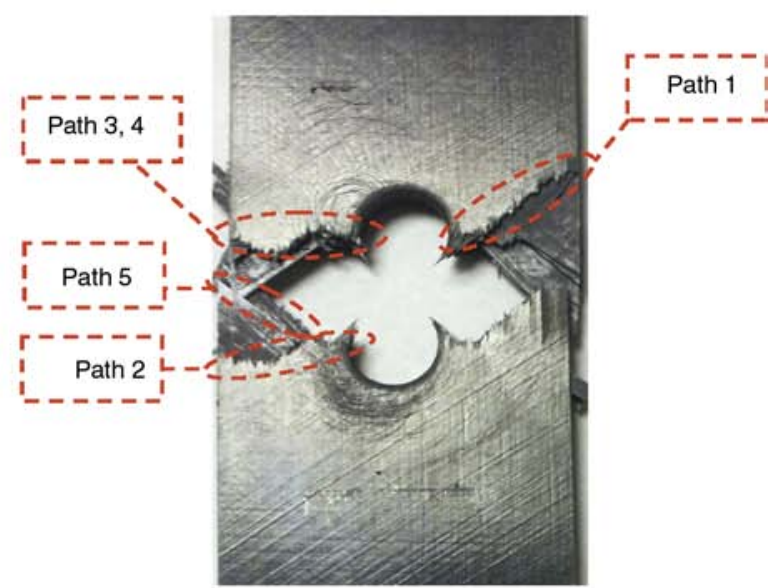

d)

SDV2 (Avg: $100 \%$ )

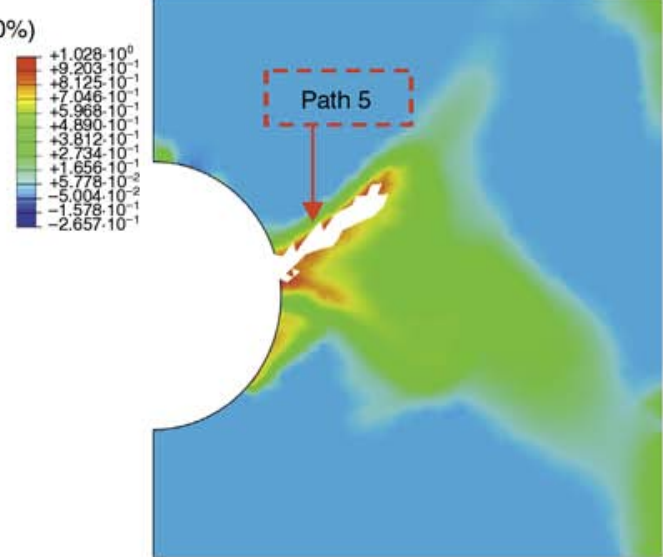

f)

Figure 9. Intra-laminar damage patterns of fiber and matrix for $[0 / 90 /-45 /+45]_{3 \mathrm{~s}}$ AS4/PEEK laminate at the time of abrupt strength reduction. $a, b, c)$ fiber damage image in $0^{\circ}$ layer for different simulation runs. d) an open-hole failed specimen under static test. e) matrix damage pattern in $90^{\circ}$ layer. f) matrix damage pattern in $45^{\circ}$ layer. 
Although the presented simulation results of progressive damage obtained from different methods are in agreement with experiments, several points about the comparison of different methods would be in order. Methods I and II have the advantage of modeling delamination, fiber and matrix failure using a damage parameter and embedded cohesive elements in the model. However, their computational time is more expensive and numerical convergence is more problematic than those of Method III. Method III uses the sudden material property degradation rule which may raises questions and difficulties in validation of numerical results for complex geometry and laminate. However, from engineering point of view, Method III is fast and may give a realistic approximation of the laminate's strength. All of these methods depend on mesh type, mesh number, viscous regularization factor, and material property degradation rule. Future works considering the above-mentioned restrictions along with more recent computational methods such as X-FEM and A-FEM with considerations of randomness in the distribution of material properties are necessary to tackle the design of open-hole or notched laminates in a more realistic manner. Further, numerical results show how the numerical results are sensitive to mesh type, viscous regularization factor and distribution of material properties. Questions such as how should the variation of material properties be chosen and how sensitive are the mesh type and size to a random function of material distribution can be answered once a realistic material morphology is available. Future research is needed to study the effect of material property distribution functions along with a realistic characterization of the laminate morphology that can be implemented in a robust computational method such as X-FEM or A-FEM. Capability to model arbitrary crack path and discrete damage in a composite laminate are thus needed.

\section{Conclusions}

The present paper presents a study of the progressive intra- and inter-laminar damage coupled with cohesive elements for the failure simulation of two quasi-isotropic open-hole AS4/PEEK laminates with $[0 / 90 /-45 /+45]_{3 s}$ and $[0 / 45 / 90 /-45 /]_{2 s}$ configurations. Three different approaches (Method I, II and III) are implemented in ABAQUS ${ }^{\mathrm{TM}}$ user sub- routine (UMAT) to simulate the degradation. Method I is a strain-based damage evolution while Method II is the modified of Method I and stressbased damage evolution proposed in this work. Method III obeys the Hashin-based degradation evolution criteria. Gaussian distribution is considered to model the scatter of material properties during the simulation. The model is applied to predict the strength of the open-hole laminate and the simulation results correlate well with the experimental data of the present work and [7]. A parametric study is performed for the effect of different mesh sizes and viscous regularization factors. The results show that in Methods I and II the damage prediction is sensitive to viscous regularization factor and mesh sizes. However, in latter, the characteristic length of the elements is considered to minimize the effect of the mesh size. The results of different damage patterns of the $0^{\circ}$ fibers indicates that depending on the stochastic material properties, the failure path differs each time the model is run. The study on the effects of Gaussian distribution of material properties shows that depending on the scattering of material properties, the damage propagation and failure path vary each time the numerical simulation is run. The failure paths obtained from re-running the simulation for several times are in close agreement with the image of fractured specimen.

\section{References}

[1] Chang K-Y., Liu S., Chang F-K.: Damage tolerance of laminated composites containing an open hole and subjected to tensile loadings. Journal of Composite Materials, 25, 274-301 (1991).

DOI: $10.1177 / 002199839102500303$

[2] Hashin Z.: Failure criteria for unidirectional fiber composites. Journal of Applied Mechanics, 47, 329-334 (1980). DOI: $10.1115 / 1.3153664$

[3] Lessard L. B., Shokrieh M.: Two-dimensional modeling of composite pinned-joint failure. Journal of Composite Materials, 29, 671-697 (1995). DOI: $10.1177 / 002199839502900507$

[4] Dano M-L., Gendron G., Picard A.: Stress and failure analysis of mechanically fastened joints in composite laminates. Composite Structures, 50, 287-296 (2000). DOI: 10.1016/S0263-8223(00)00119-7

[5] İçten B. M., Karakuzu R.: Progressive failure analysis of pin-loaded carbon-epoxy woven composite plates. Composites Science and Technology, 62, 1259-1271 (2002).

DOI: $10.1016 / \mathrm{S} 0266-3538(02) 00071-4$ 
[6] Hoffman O.: The brittle strength of orthotropic materials. Journal of Composite Materials, 1, 200-206 (1967). DOI: $10.1177 / 002199836700100210$

[7] Maa R-H., Cheng J-H.: A CDM-based failure model for predicting strength of notched composite laminates. Composites Part B: Engineering, 33, 479-489 (2000). DOI: 10.1016/S1359-8368(02)00030-6

[8] Ding S., Tong J. W., Wang Z. Y., Huo Y.: Fracture characters and damage mechanism of the notched AS4/ PEEK composite laminate. Journal of Thermoplastic Composite Materials, 23, 565-581 (2010). DOI: 10.1177/0892705709347094

[9] Lapczyk I., Hurtado J. A.: Progressive damage modeling in fiber-reinforced materials. Composites Part A: Applied Science and Manufacturing, 38, 2333-2341 (2007). DOI: 10.1016/j.compositesa.2007.01.017

[10] Falzon B. G., Apruzzese P.: Numerical analysis of intralaminar failure mechanisms in composite structures. Part II: Applications. Composite Structures, 93, 1047-1053 (2011). DOI: $10.1016 /$ j.compstruct.2010.06.022

[11] Camanho P. P., Maimí P., Dávila C. G.: Prediction of size effects in notched laminates using continuum damage mechanics. Composites Science and Technology, 67, 2715-2727 (2007).

DOI: 10.1016/j.compscitech.2007.02.005

[12] Abisset E., Daghia F., Ladevèze P.: On the validation of a damage mesomodel for laminated composites by means of open-hole tensile tests on quasi-isotropic laminates. Composites Part A: Applied Science and Manufacturing, 42, 1515-1524 (2011). DOI: 10.1016/j.compositesa.2011.07.004

[13] van der Meer F. P., Sluys L. J., Hallett S. R., Wisnom M. R.: Computational modeling of complex failure mechanisms in laminates. Journal of Composite Materials, 46, 603-623 (2012).

DOI: $10.1177 / 0021998311410473$

[14] Fang X. J., Zhou Z. Q., Cox B. N., Yang Q. D.: Highfidelity simulations of multiple fracture processes in a laminated composite in tension. Journal of the Mechanics and Physics of Solids, 59, 1355-1373 (2011).

DOI: 10.1016/j.jmps.2011.04.007

[15] Daghia F., Ladevèze P.: A micro-meso computational strategy for the prediction of the damage and failure of laminates. Composite Structures, 94, 3644-3653 (2012). DOI: $10.1016 /$ j.compstruct.2012.05.028

[16] van der Meer F. P., Sluys L. J.: A phantom node formulation with mixed mode cohesive law for splitting in laminates. International Journal of Fracture, 158, 107 124 (2009).

DOI: $10.1007 / \mathrm{s} 10704-009-9344-5$
[17] Moës N., Belytschko T.: Extended finite element method for cohesive crack growth. Engineering Fracture Mechanics, 69, 813-833 (2002).

DOI: $10.1016 / \mathrm{S} 0013-7944(01) 00128-\mathrm{X}$

[18] Yang Q. D., Liu W., Mohammadizadeh S., Su X-Y., Ling D-S.: An accurate and efficient A-FEM for arbitrary crack interactions. Journal of Mechanics of Materials, in press (2013).

DOI: $10.1115 / 1.4007970$

[19] Hansbo A., Hansbo P.: A finite element method for the simulation of strong and weak discontinuities in solid mechanics. Computer Methods in Applied Mechanics and Engineering, 193, 3523-3540 (2004).

DOI: $10.1016 /$ j.cma.2003.12.041

[20] Camanho P. P., Dávila C. G.: Mixed-mode decohesion finite elements for the simulation of delamination in composite materials. NASA/TM-2002-211737 2002, 1-37 (2002).

[21] Linde P., Pleitner J., Boer H., Carmone C.: Modeling and simulation of fiber metal laminates. in 'ABAQUS users' Conference, Boston, USA' 421-439 (2004).

[22] ABAQUS/standard version 6.10. User Manual, Hibbit, Karlsson and Sorensen Inc., Rhode Island, USA (2010).

[23] Benzeggagh M. L., Kenane M.: Measurement of mixedmode delamination fracture toughness of unidirectional glass/epoxy composites with mixed-mode bending apparatus. Composites Science and Technology, 56, 439-449 (1996). DOI: $10.1016 / 0266-3538(96) 00005-X$

[24] Wu E. M., Reuter R. C.: Crack extension in fiberglass reinforced plastics. T\&M Report 275, University of Illinois, USA (1965).

[25] Reeder J., Kyongchan S., Chunchu P. B., Ambur R.: Postbuckling and growth of delaminations in composite plates subjected to axial compression. in 'AIAA/ ASME/ASCE/AHS/ASC Structures, Structural Dynamics, and Materials Conference, Denver, Colorado' p.10 (2002).

[26] Camanho P. P., Daliva C., G., de Moura M. F.: Numerical simulation of mixed-mode progressive delamination in composite materials. Journal of Composite Materials, 37, 1415-1438 (2003).

DOI: $10.1177 / 0021998303034505$

[27] Camanho P. P., Matthews F. L.: A progressive damage model for mechanically fastened joints in composite laminates. Journal of Composite Materials, 33, 22482280 (1999).

DOI: $10.1177 / 002199839903302402$

[28] Tan S. C., Nuismer R. J.: A theory for progressive matrix cracking in composite laminates. Journal of Composite Materials, 23, 1029-1047 (1989). DOI: 10.1177/002199838902301006

[29] Reeder J. R., Crews J. R.: Mixed-mode bending method for delamination testing. AIAA Journal, 28, 1270-1276 (1990). 